\title{
Combination of Tamsulosin with Potassium Citrate Effect on Serum Oxidoreductases in Patients with Nephrolithiasis
}

\author{
JWAN A. ZAINULABDEEN ${ }^{1 *}$, OMAR K. SUHAIL ${ }^{1}$ and AHMED H. SAIFALLAH ${ }^{2}$ \\ ${ }^{1}$ Department of Chemistry, College of Sciences, University of Baghdad, Baghdad, Iraq. \\ ${ }^{2}$ Al-kindy teaching Hospital, Baghdad, Iraq. \\ ${ }^{*}$ Corresponding E-mail address: omarsuhail92@gmail.com \\ http://dx.doi.org/10.13005/ojc/340362
}

(Received: January 18, 2018; Accepted: May 30, 2018)

\begin{abstract}
This study was designed to prove the probable effect of oral treatment (combination of tamsulosin with potassium citrate) on serum xanthine oxidoreductases and oxidative stress levels for patients with nephrolithiasis. A total of 55 newly diagnosed nephrolithiasis patients (P1 group) were involved in this study matched with 30 apparently healthy volunteers (C group); 22 of the patients (P2 group) were followed after treatment. Blood urea, creatinine, uric acid, total serum protein (TSP), and albumin were measured by using Abbott c400 analyzer. Colorimetric methods were used to detect total antioxidant status (TOS), total antioxidant status (TAS), oxidative stress index (OSI), xanthine oxidoreductases enzymes (xanthine oxidase (XO) and xanthine dehydrogenase (XDH)) and other biochemical parameters. One-way ANOVA test was used for data analysis. For P1 group in comparison to that of $C$ and $P 2$ groups, the observed results were as follows: significant increases were observed in serum urea, creatinine, MDA, TOS, TAS, OSI, XO, and UA, $p=0.007, p=0.001, p=0.000, p=0.000$, $p=0.000, p=0.002, p=0.039$ respectively, while significant decreases were indicated $X D H, T S P$, and albumin, $p=0.000, p=0.001, p=0.001$ respectively. Meanwhile, the measured parameters were exhibited a good alteration after treatment (TOS and TAS were significantly decreased, while TSP and albumin were slightly increased). The present study suggests that the used treatment success in balancing the oxidative stress of nephrolithiasis patients by decreasing the oxidants and increasing the antioxidant parameters leading to prevent the renal damage.
\end{abstract}

Keywords: Nephrolithiasis, Tamsulosin, Potassium citrate, Oxidoreductases, and Oxidative stress.

\section{INTRODUCTION}

Nephrolithiasis is a complex disease prevailing worldwide, affected by two main factors: genetic and environmental; recently studies found that family history, lifestyle modification diet, low intake of fluids, and obesity are effect factors that play a role in the development of nephrolithiasis ${ }^{1,2}$. In nephrolithiasis polycrystalline accumulations were obtained; caused by a disorder of the equilibrium between solubility and accumulation of salts in kidneys, composed of varying amount of crystalloid and organic compounds, and formed inside the kidney wherever urine collects ${ }^{3}$. Kidney stones may

This is an Open Access article licensed under a Creative Commons Attribution-Non Commercial-Share Alike 4.0 International License (https://creativecommons.org/licenses/by-nc-sa/4.0/), which permits unrestricted Non Commercial use, distribution and reproduction in any medium, provided the original work is properly cited. 
have various compositions which include: calcium oxalate $(\mathrm{CaOx})$, calcium phosphate $(\mathrm{CaP})$, and uric acid $(\mathrm{UA})^{4}$. For treatment, potassium citrate has been applied as an oral alkalinizing agent, it reduces the saturation of kidney stones by inhibiting crystallization and enlargement of the stones by decreasing citrate uptake, increasing citrate excretion in addition of its effect on $\mathrm{pH}^{4-5}$. Meanwhile, tamsulosin hydrochloride is a selective nephrolithiasis treatment as alpha1 -adrenoceptor, acts as a blocking agent and originally used to decrease the procedure required for stone removal or passage ${ }^{6-9}$. In kidney tissue, the reactive oxygen species (ROS) lead to injury or inflammation during the interactions between the crystals and renal cells and are responsible for the various cellular responses; $\mathrm{CaOx}$ crystals generally form in the renal tubules ${ }^{10-12}$. Oxalate-induced membrane injury is mediated by lipid peroxidation (LPO), an oxidation process of polyunsaturated fatty acids to generate oxygen free radicals and give malondialdehyde $(\mathrm{MDA})^{13}$. Xanthine oxidoreductases (XOR, $\mathrm{XDH} / \mathrm{XO}$ ) is responsible for the oxidation of hypoxanthine to xanthine to generate $U A$ and $R S^{14}$. In normal tissues, the enzyme exists as XDH (XDH, $E C$ 1.17.1.4), utilizing $N A D^{+}$as coenzyme rather than of $\mathrm{O}_{2}$ as the electron acceptor. XDH can be readily converted to the oxidase (XO, EC 1.17.3.2) form irreversibly by either the oxidation of sulfhydryl residues or proteases; XO considered as a first biological source of $\left(\mathrm{O}^{\circ}{ }^{-}\right)$and a key mediator of cell damage ${ }^{15-16}$. Hyperuricemia cause by increasing UA production or reduced excretion, at all cause give reduction glomerular filtration, tubular excretion or increased reabsorption would result in an elevated serum $\mathrm{UA}^{17}$. The aim of current work is to study the effect of tamsulosin hydrochloride and potassium citrate treatment on some oxidative stress markers in Iraqi patients with nephrolithiasis.

\section{MATERIALS AND METHODS}

Three groups were included in this study; newly diagnosed 55 male patients with nephrolithiasis before treatment ( $\mathrm{P} 1$ group) and 30 apparently healthy controls comparable for age and gender and without a history of nephrolithiasis (C group) were involved in the current study. Twentytwo of these (55) patients were attending after being treated with tamsulosin hydrochloride and potassium citrate treatments for one week (P2 group). All patients underwent kidney ultrasound screening through ultra-sonographer, P2 group were treated with a combination of tamsulosin hydrochloride (in a dose of $0.4 \mathrm{mg}$ ) and sodium-potassiumhydrogen citrate (Uralyt-U® from Cid - Madaus, Germany) in the morning after breakfast for a week. This treatment was given daily in three divided doses to get a urinary pH between 6.2 and 6.8. The first dose involved one measure spoonful. The samples were collected from patients who were attending to Al-kindy teaching hospital in Baghdad, Iraq. Venous blood samples were collected from an antecubital vein (8.00-12.00 a.m.) after the 10-12 h overnight fasting period. The obtained sample was centrifuged at $3000 \mathrm{xg}$ for $5 \mathrm{~min}$ and the collected serum was stored at $-27^{\circ} \mathrm{C}$. In the current study Patients with diabetes mellitus, diabetic nephropathy, heart disease, taking a potent antioxidant, history of alcohol intake, females, smokers and patients with Stones less than $5 \mathrm{~mm}$ were excluded. This study protocol was approved by the Ethics Committee of the College of Science/ University of Baghdad. The serum XO and XDH were measured according to the Ackermann method ${ }^{18}$. Levels of OSI, total oxidant status (TOS) and total antioxidant status (TAS) in the serum of studied group were measured according to methods developed by Erel ${ }^{19-20}$. A modified method of Satoh was used to measure malondialdehyde (MDA) $)^{21}$. Also, other biochemical parameters included: fasting blood sugar, blood urea, creatinine, total serum protein (TSP), albumin, lipid profile and uric acid were measured by Abbott c400 analyzer. Globulin concentration in sera samples of the studied groups in this study was calculated from the following equation:

Globulin conc. $(\mathrm{g} / \mathrm{L})=$ Total protein conc. - Albumin conc.

The data analysis was conducted by using a statistics software package (SPSS for Windows v.22.0). All groups showed normal distribution so that parametric statistical methods were used to analysis the data. One-way ANOVA followed by Tukey analysis to test the differences between groups, and the $P$-value was considered significant if it is $<0.05$. Results are presented as means \pm SD. 


\section{RESULTS}

The mean ages of the three groups ( $\mathrm{P} 1, \mathrm{P} 2$, and $\mathrm{C}$ ) was (30.55 vs. 30.14 vs. 30.62 years) respectively, (Table 1), there were non-significant different $(p>0.05)$ in the mean values of glucose and lipid profile of all the three studied groups (control group $(\mathrm{C})$, patient before treatment group (P1), patient after treatment group (P2).

A highly significant increase of serum urea and creatinine levels $p=0.007$ and $p=0.001$ respectively in $\mathrm{P} 1$ group was observed in comparison with their levels in (P2) and (C) groups. TSP and albumin concentrations were significantly decreased $p=0.001, p=0.001$ in (P1) group when compared with control group. While After treatment, urea and creatinine were slightly decrease in $\mathrm{P} 2$ group is observed but the decrease was non-significant $p=0.091, p=0.062$ respectively. Both of TSP and albumin levels were slightly increased in a P2 group. No significant difference was found in serum globulin among the three groups. Above results are illustrated in (Table 2).

Table 1: Age, Glucose, Cholesterol, Triglycerides, and HDL concentrations of the three studied groups

\begin{tabular}{lccccc}
\hline $\begin{array}{l}\text { Parameters } \\
\text { HDL }\end{array}$ & $\begin{array}{c}\text { Age } \\
\text { (year) }\end{array}$ & $\begin{array}{c}\text { F.BG } \\
\mathrm{mg} / \mathrm{dl}\end{array}$ & $\begin{array}{c}\text { Chol. } \\
\mathrm{mg} / \mathrm{dl}\end{array}$ & $\begin{array}{c}\mathrm{TG} \\
\mathrm{mg} / \mathrm{dl}\end{array}$ & $\begin{array}{c}\mathrm{HDL} \\
\mathrm{mg} / \mathrm{dl}\end{array}$ \\
\hline $\mathrm{C}(\mathrm{n}=30)$ & $30.14 \pm 6.73$ & $94.68 \pm 18.72$ & $158.02 \pm 27.21$ & $137.52 \pm 50.19$ & $41.50 \pm 7.11$ \\
$\mathrm{P} 1(\mathrm{n}=55)$ & $30.55 \pm 6.81$ & $104.14 \pm 23.87$ & $166.05 \pm 27.75$ & $131.04 \pm 51.48$ & $40.81 \pm 5.70$ \\
$\mathrm{P} 2(\mathrm{n}=22)$ & $30.62 \pm 6.90$ & $96.71 \pm 12.88$ & $163.87 \pm 26.1$ & $142.55 \pm 53.56$ & $39.68 \pm 8.07$ \\
\hline
\end{tabular}

$\mathrm{C}=($ control group $), \mathrm{P} 1=$ (before treatment patient), $\mathrm{P} 2=($ after treatment patient $)$

Table 2: Concentrations of Urea, Creatinine, Proteins in the sera of the three studied groups

\begin{tabular}{lccccc}
\hline Parameters & $\begin{array}{c}\text { Urea } \\
(\mathrm{mg} / \mathrm{dL})\end{array}$ & $\begin{array}{c}\text { Creatinine } \\
(\mathrm{mg} / \mathrm{dL})\end{array}$ & $\begin{array}{c}\text { TSP } \\
(\mathrm{g} / \mathrm{dL})\end{array}$ & $\begin{array}{c}\text { Albumin } \\
(\mathrm{g} / \mathrm{dL})\end{array}$ & $\begin{array}{c}\text { Globulin } \\
(\mathrm{g} / \mathrm{dL})\end{array}$ \\
\hline $\mathrm{C}(\mathrm{n}=30)$ & $25.23 \pm 4.32$ & $0.72 \pm 0.07$ & $7.58 \pm 0.28$ & $4.55 \pm 0.18$ & $3.02 \pm 0.2$ \\
$\mathrm{P} 1(\mathrm{n}=55)$ & $30.81 \pm 7.62$ & $0.91 \pm 0.09$ & $7.06 \pm 0.39$ & $4.17 \pm 0.37$ & $2.98 \pm 0.33$ \\
p value & $0.007^{\star *} \mathrm{a}$ & $0.001^{* *} \mathrm{a}$ & $0.001^{* *} \mathrm{a}$ & $0.001^{\star *} \mathrm{a}$ & 0.125 \\
P2 ( $\mathrm{n}=22)$ & $26.71 \pm 4.30$ & $0.75 \pm 0.09$ & $7.40 \pm 0.34$ & $4.38 \pm 0.24$ & $3.02 \pm 0.42$ \\
$\mathrm{p}$ value & 0.091 & 0.062 & 0.242 & 0.320 & 0.342 \\
\hline
\end{tabular}

$\mathrm{C}=$ (control group), $\mathrm{P} 1=$ (before treatment patient), $\mathrm{P} 2=$ (after treatment patient)

${ }^{*} p<0.05 ;{ }^{* *} p<0.01 ;{ }^{* *} p<0.001$; no asterisk: $p \geq 0.05$. $a=$ comparison between groups (C) and (P1)

In comparison with (C) group, serum TAS, TOS, OSI and MDA in (P1) were significantly increased $p=0.000, p=0.000, p=0.000, p=0.002$, $\mathrm{p}=0.039$ respectively. while the TOS, TAS levels in (P2) group were significant decrease $p=0.009$, $\mathrm{p}=0.000$ respectively compare with (P1) group. besides, MDA in (P2) group was slightly decrease but non-significant $(p=0.08)$ in (Table 1$)$.
The present study showed that mean levels of serum $X O$ and UA in (P1) group showed the significant increase at $\mathrm{p}=0.028, \mathrm{P}=0.039$ respectively in comparison with (C) groups. furthermore, levels of serum $\mathrm{XDH}$ in (P1) group was a highly significant decrease $(p=0.000)$ compared to $(C)$ group. Meanwhile, the levels of $\mathrm{XO}, \mathrm{XDH}$, and UA were altered (but not significantly) after treatment, in (Table 4). 
Table 3: Comparison of serum MDA, TOS, TAS, and OSI in sera of the three studied groups

\begin{tabular}{|c|c|c|c|c|}
\hline Parameters & $\begin{array}{c}\mathrm{MDA} \\
(\mathrm{nmol} / \mathrm{mL})\end{array}$ & $\begin{array}{c}\text { TOS } \\
(\mathrm{mmol} \\
\left.\mathrm{H}_{2} \mathrm{O}_{2} \mathrm{Eq} / \mathrm{L}\right) \\
\end{array}$ & $\begin{array}{c}\text { TAS } \\
\text { (mmol glutathione } \\
\text { Eq./L) }\end{array}$ & OSI \\
\hline$C \quad(n=30)$ & $2.505 \pm 0.521$ & $0.0159 \pm 0.0072$ & $0.3601 \pm 0.089$ & $0.046 \pm 0.022$ \\
\hline$P 1(n=55)$ & $3.522 \pm 0.733$ & $0.0299 \pm 0.0115$ & $0.464 \pm 0.065$ & $0.065 \pm 0.027$ \\
\hline$p$ value & $0.000^{\star \star \star} \mathrm{a}$ & $0.000^{\star \star \star} \mathrm{a}$ & $0.000^{\star \star \star} \mathrm{a}$ & $0.002^{\star \star} \mathrm{a}$ \\
\hline$P 2(n=22)$ & $3.125 \pm 0.675$ & $0.0220 \pm 0.0069$ & $0.3802 \pm 0.072$ & $0.060 \pm 0.022$ \\
\hline$p$ value & 0.08 & $0.009^{\star *} \mathrm{~b}$ & $0.000^{\star * *} \mathrm{~b}$ & 0.706 \\
\hline
\end{tabular}

Table 4: Comparison of serum XO, XDH, activities and UA concentrations in sera of the three studied groups

\begin{tabular}{lccc}
\hline Parameters & $\begin{array}{c}\text { XO } \\
\text { activity } \\
(\mathrm{U} / \mathrm{L})\end{array}$ & $\begin{array}{c}\text { XDH } \\
\text { activity } \\
(\mathrm{U} / \mathrm{L})\end{array}$ & $\begin{array}{c}\text { UA } \\
(\mathrm{mg} / \mathrm{dl})\end{array}$ \\
\hline $\mathrm{C}(\mathrm{n}=30)$ & $76.14 \pm 13.99$ & $0.726 \pm 0.187$ & $6.096 \pm 0.868$ \\
$\mathrm{P} 1(\mathrm{n}=55)$ & $101.62 \pm 29.22$ & $0.533 \pm 0.159$ & $6.66 \pm 0.927$ \\
$\mathrm{p}$ value & $0.028^{*} \mathrm{a}$ & $0.000^{* * *} \mathrm{a}$ & $0.039^{*} \mathrm{a}$ \\
$\mathrm{P} 2(\mathrm{n}=22)$ & $91.15 \pm 26.34$ & $0.602 \pm 0.119$ & $6.41 \pm 0.926$ \\
$\mathrm{p}$ value & 0.655 & 0.434 & 0.706 \\
\hline
\end{tabular}

$\mathrm{C}$ (control group), P1 (before treatment patient), P2 (after treatment patient)

${ }^{*} \mathrm{p}<0.05 ;{ }^{* *} \mathrm{p}<0.01 ;{ }^{* \star *} \mathrm{p}<0.001$; no asterisk: $\mathrm{p} \geq 0.05$. $a=$ comparison between groups $(\mathrm{C})$ and $(\mathrm{P} 1)$

\section{DISCUSSION}

In this study serum of fifty-five untreated males with nephrolithiasis, Twenty-two of treated patients, and thirty of apparently healthy individuals were used to follow the variation in the levels of xanthine oxidoreductases enzymes (XO and $\mathrm{XDH})$ ) and other biochemical parameters related to oxidative stress. In this study, male with high pressure, obese, and diabetics were excluded, because significant relationships were found between nephrolithiasis and obesity, diabetes and, high blood pressure ${ }^{22-23}$.

The results indicated significant increases in the levels of urea, creatinine in (P1) group,
(Table 2), Increased serum creatinine concentration does generally equate to impaired kidney function ${ }^{24}$, the causative is implications of a kidney stone, which impaired kidney function whereas the main role of the kidney is to excrete metabolic wastes ${ }^{25-26}$. Combination of tamsulosin with potassium citrate treatment able to dissolve stones, sometimes allowed to pass the stones before their complete dissolution, thus serum urea and creatinine levels decreased in (P2) group when compared with (P1) group. The results showed a decrease in the concentration of serum total protein and albumin in (P1) group when compared to the control group and (P2) group, (Table 2). Serum albumin is the most abundant serum protein, it has multiple functions, such as antioxidant, 
absorbs ROS and prevents them from attacking other essential proteins ${ }^{27-29}$ Also It helps to retain elements like calcium, some hormones, and certain drugs in the circulation by binding to them to prevent their being filtered out by the kidneys ${ }^{30}$. Furthermore, it has been suggested that the decrease in serum [TP] is due to microproteinuria and albuminuria, which are important clinical markers of kidney disease ${ }^{31}$ Interference with mastication, digestion or deglutition of food cause malnutrition and lead to decrease liver synthesis of albumin ${ }^{30}$. besides, the acute-phase response to inflammation results in a decrease in the gene transcription rates and thus a synthesis of albumin as a negative acute-phase proteins ${ }^{32}$. Oxidative stress is formed by an imbalance between antioxidants and oxidants ${ }^{33}$. Free radicals are pro-oxidants, normally result from the biochemical redox reactions of cellular metabolism, they cause renal epithelial cell injury by the LPO reaction.

In the present study, the levels of biochemical parameters related to oxidative stress, (Table 3 ), were also increased in $\mathrm{P} 1$ group as compared with $C$ and $P$ groups, it revealed high levels of TOS, MDA, OSI, and UA. This result is in parallel with several studies that showed the presence of the significant increase in these parameters between patients with nephrolithiasis and healthy controls ${ }^{34-38}$. The increase of (TAS) in P1 group may be due to the action of the immune system which increases antioxidants activities to detoxify the effect of the produced free radicals, it is worthwhile to supplement the patients with antioxidants so as to combat the oxidative load in the body, and also to replenish the anti-oxidants in the body ${ }^{39-40}$. Previous studies have found that potassium citrate has the potential ability to maintain renal epithelial cells from damage by decreasing free radical production and preventing MDA formation 5,41 , meanwhile, the levels of oxidative stress marker (TAS, TOS, MDA, and OSI) were significant decreased in patients after treatment (P2 group), possibly the used treatment provide suitable $\mathrm{pH}$ to pass the stones before their complete dissolution, causing reducing free radical production, so it protecting renal epithelial cells from further injury, oxidative stress marker, and blocking lipid peroxidation reaction compared with (P1 group) 5.

Xanthine oxidoreductase (XOR; XO and $X D H$ ) is a ubiquitous complex cytosolic molybdoflavoprotein which regulates the rate-limiting step of purine catabolism by transforming xanthine to $U A^{42}$. We found significant increases in the serum XO activities as well as UA levels with highly significant decrease in serum $\mathrm{XDH}$ activities in patients before treatment with nephrolithiasis, compared with the two other groups (Table 4), the results were agreed with other studies which indicate that XO levels are increased in several pathological states like inflammation, ischemiareperfusion, aging, atherosclerosis and recently, in sera of Malaysian patients with kidney stone disease, however, UA is an independent risk factor for kidney disease ${ }^{18,40,43}$. The results can be explained as follows: increased urinary excretion of oxalate (Ox), hyperoxaluria, can be toxic largely because of its propensity to crystallize at physiologic $\mathrm{pH}$ and form calcium oxalate $(\mathrm{CaOx})$ crystal deposits in the kidneys leading to the production of ROS development of oxidative stress followed by injury and inflammation ${ }^{12}$. In hyperoxaluria, the XDH was converted to $\mathrm{XO}$; serum $\mathrm{XO}$ is a critical source of (ROS) as a source of $\left(\mathrm{O}_{2}{ }^{--}\right)$and assumes $\mathrm{H}_{2} \mathrm{O}_{2}{ }^{44}$, this means, both $\left(\mathrm{O}_{2}{ }^{-}\right)$and the $\left(\mathrm{OH}^{\bullet}\right)$ are produced in excess under oxalate stress conditions ${ }^{45}$. So in a condition in which excessive oxalate formation was present, the activity of $\mathrm{XO}$ in ischaemicreperfused kidney stone was higher than that of control ischaemic reperfused kidney. After treatment (P2 group) $\mathrm{XDH}$ activity was increased; returning to near to the control levels in comparison with (P1) , (Table 4), at variance of decreasing XO, MDA and TOS levels (Table 3 ), that may be because of the effect of combined of potassium citrate with tamsulosin hydrochloride treatment, causing reducing free radical production, thus protecting renal epithelial cells from further injury, and blocking lipid peroxidation reaction ${ }^{5,41}$. Generally, the studied parameters were modified after treatment (in P2 group), which reflect the advantage of the treatment (combination of tamsulosin with potassium citrate) utilization for nephrolithiasis patients to pass the stones and to prevent renal damage by decreasing the oxidative stress. As a conclusion; serum concentrations of oxidative stress parameters such as oxidoreductases enzymes activities ( $\mathrm{XO}$ and $\mathrm{XDH}$ ) were affected by formation of kidney stones, as well as the combination of potassium citrate with tamsulosin was effective for nephrolithiasis; via decreasing oxidants levels (XO, MDA, TOS, and 
OSI) and modulating antioxidants levels (TAS, XDH, and albumin). Serum XDR activities may be used as diagnostic tool for nephrolithiasis (further search wanted; which are work in our laboratory).

\section{REFERENCES}

1. Goldfarb, D. S.; Fischer, M. E.; Keich, Y.; Goldberg, J., A twin study of genetic and dietary influences on nephrolithiasis: a report from the Vietnam Era Twin (VET) Registry. Kidney international., 2005, 67(3), 1053-1061.

2. Hayatdavoudi, P.; Rad, A. K.; Rajaei, Z.; Hadjzadeh, M. A.-R., Renal injury, nephrolithiasis and Nigella sativa: A mini review. Avicenna journal of phytomedicine., 2016, 6(1), 1.

3. Han, H.; Segal, A. M.; Seifter, J. L.; Dwyer, J. T., Nutritional management of kidney stones (nephrolithiasis). Clinical nutrition research., 2015, 4(3), 137-152.

4. Suarez, M.; Youssef, R. F., Potassium citrate: treatment and prevention of recurrent calcium nephrolithiasis. J Clin Nephro Res., 2015, 2, 1015-1011.

5. Tungsanga, K.; Sriboonlue, P.; Futrakul, P.; Yachantha, C.; Tosukhowong, P., Renal tubular cell damage and oxidative stress in renal stone patients and the effect of potassium citrate treatment. Urological research., 2005, 33(1), 65-69.

6. Miller, O. F.; Kane, C. J., Time to stone passage for observed ureteral calculi: a guide for patient education. The Journal of urology., 1999, 162(3), 688-691.

7. Xu, H.; Zisman, A. L.; Coe, F. L.; Worcester, E. M., Kidney stones: an update on current pharmacological management and future directions. Expert opinion on pharmacotherapy., 2013, 14(4), 435-447.

8. Pourmand, A.; Nadendla, R.; MazerAmirshahi, M.; O'connell, F., Tamsulosin for urolithiasis: a review of the recent literature and current controversies. The American journal of emergency medicine., 2016, 34 (11), 2217-2221.

9. Lipkin, M.; Shah, O., The use of alphablockers for the treatment of nephrolithiasis.

Reviews in urology., 2006, 8(4), S35.

10. Khan, S. R., Reactive oxygen species as the molecular modulators of calcium oxalate kidney stone formation: evidence from clinical and experimental investigations. The Journal of urology., 2013, 189(3), 803-811.

11. Khan, S. R., Reactive oxygen species, inflammation and calcium oxalate nephrolithiasis. Translational andrology and urology., 2014, 3(3), 256.

12. Khan, S. R., Hyperoxaluria-induced oxidative stress and antioxidants for renal protection. Urological research., 2005, 33(5), 349-357.

13. Selvam, R., Calcium oxalate stone disease: role of lipid peroxidation and antioxidants. Urological research., 2002, 30(1), 35-47.

14. Cao, H.; Pauff, J. M.; Hille, R., X-ray crystal structure of a xanthine oxidase complex with the flavonoid inhibitor quercetin. Journal of natural products., 2014, 77(7), 1693-1699.

15. Harrison, R., Structure and function of xanthine oxidoreductase: where are we now? Free Radical Biology and Medicine., 2002, 33 (6), 774-797.

16. Kuwabara, Y.; Nishino, T.; Okamoto, K.; Matsumura, T.; Eger, B. T.; Pai, E. F.; Nishino, T., Unique amino acids cluster for switching from the dehydrogenase to oxidase form of xanthine oxidoreductase. Proceedings of the National Academy of Sciences., 2003, 100 (14), 8170-8175.

17. Poudel, B.; Yadav, B. K.; Kumar, A.; Jha, B.; Raut, K. B., Serum uric acid level in newly diagnosed essential hypertension in a Nepalese population: a hospital based cross sectional study. Asian Pacific journal of tropical biomedicine., 2014, 4(1), 59-64.

18. Yusof, F.; Mehde, A. A.; Mehdi, W. A.; Ghazali, H.; Rahman, A. A., Study the effect of kidney stones on serum xanthine oxidase, ecto-5-nucleotidase activity and E3 SUMOprotein ligase NSE2 (NSMCE2) in Malaysian individuals. Asian Pacific Journal of Tropical Biomedicine., 2015, 5(8), 684-688.

19. Erel, O., A novel automated method to measure total antioxidant response against potent free radical reactions. Clinical biochemistry., 2004, 37(2), 112-119.

20. Erel, O., A new automated colorimetric method for measuring total oxidant status. Clinical biochemistry., 2005, 38(12), 1103-1111. 
21. Hunter, M.; Nlemadim, B.; Davidson, D., Lipid peroxidation products and antioxidant proteins in plasma and cerebrospinal fluid from multiple sclerosis patients. Neurochemical research., 1985, 10(12), 1645-1652.

22. Sofia, N. H.; Walter, T. M., Prevalence and risk factors of kidney stone. Global Journal For Research Analysis., 2016, 5(3).

23. Obligado, S.H.; Goldfarb, D. S., The association of nephrolithiasis with hypertension and obesity: a review. American journal of hypertension., 2008, 21(3), 257-264.

24. Shemesh, O.; Golbetz, H.; KRIss, J. P.; Myers, B. D., Limitations of creatinine as a filtration marker in glomerulopathic patients. Kidney international., 1985, 28(5), 830-838.

25. Rule, A. D.; Krambeck, A. E.; Lieske, J. C., Chronic kidney disease in kidney stone formers. Clinical Journal of the American Society of Nephrology., 2011, 6(8), 2069-2075.

26. O'Hare, A. M.; Bertenthal, D.; Covinsky, K. E.; Landefeld, C. S.; Sen, S.; Mehta, K.; Steinman, M. A.; Borzecki, A.; Walter, L. C., Mortality risk stratification in chronic kidney disease: one size for all ages? Journal of the American Society of Nephrology., 2006, 17 (3), 846-853.

27. Nimse, S. B.; Pal, D., Free radicals, natural antioxidants, and their reaction mechanisms. Rsc Advances., 2015, 5(35), 27986-28006.

28. Prakash, S., Role of Human Serum Albumin and Oxidative Stress in Diabetes. J Appl Biotechnol Bioeng., 2017, 3(1), 00057.

29. McGuinness, A. J. A.; Sapey, E., Oxidative stress in COPD: sources, markers, and potential mechanisms. Journal of clinical medicine., 2017, 6(2), 21.

30. Vasudevan, D. M.; Sreekumari, S.; Vaidyanathan, K., Textbook of biochemistry for medical students. JP Medical Ltd., 2013.

31. Ahmed, S.; Laila, T.; Begum, H.; Moniruzzaman, M., Proteinuria in chronic kidney disease and its management. Medicine Today., 2013, 25 (1), 36-41.

32. Mallikarjunappa, S.; Prakash, M., Urine protein thiols in chronic renal failure patients. Indian Journal of Nephrology., 2007, 17(1), 7.

33. Putri, A.Y.; Thaha, M., Role of oxidative stress on chronic kidney disease progression. Acta Medica Indonesiana., 2016, 46(3).

34. Aggarwal, D.; Sharma, M.; Singla, S., The role of natural antioxidants as potential therapeutic agent in Nephrolithiasis. Asian $J$ Pharm Clin Res., 2013, 6(3), 48-53.
35. Malle, E.; Buch, T.; Grone, H.-J., Myeloperoxidase in kidney disease. Kidney international., 2003, 64(6), 1956-1967.

36. Karaolanis, G.; Lionaki, S.; Moris, D.; Palla, V.-V.; Vernadakis, S., Secondary hyperoxaluria: a risk factor for kidney stone formation and renal failure in native kidneys and renal grafts. Transplantation Reviews., 2014, 28(4), 182-187.

37. Mehde, A. A.; Mehdi, W. A.; Yusof, F.; Raus, R. A.; Abidin, Z.; Azira, Z.; Ghazali, H.; Abd Rahman, A., Association of MMP-9 gene polymorphisms with nephrolithiasis patients. Journal of clinical laboratory analysis., 2018, 32(1).

38. Mehde, A. A.; Mehdi, W. A.; Yusof, F.; Raus, R. A.; Abidin, Z. A. Z.; Ghazali, H.; Rahman, A. A., Determination of alpha-2-MRAP gene polymorphisms in nephrolithiasis patients. International journal of biological macromolecules., 2017, 105, 1324-1327.

39. Shivprasad, S.; Sonoli, S.; Patil, A. B., Oxidative Stress and Total Antioxidant Capacity in Renal Failure and Renal Calculi Patients-A Cross Sectional Study., 2013.

40. Rahal, A.; Kumar, A.; Singh, V.; Yadav, B.; Tiwari, R.; Chakraborty, S.; Dhama, K., Oxidative stress, prooxidants, and antioxidants: the interplay. BioMed research international., 2014, 2014.

41. El-Gamal, O.; El-Bendary, M.; Ragab, M.; Rasheed, M., Role of combined use of potassium citrate and tamsulosin in the management of uric acid distal ureteral calculi. Urological research., 2012, 4O(3), 219-224.

42. Agarwal, A.; Banerjee, A.; Banerjee, U., Xanthine oxidoreductase: a journey from purine metabolism to cardiovascular excitationcontraction coupling. Critical reviews in biotechnology., 2011, 31(3), 264-280.

43. Fridovich, I., Quantitative aspects of the production of superoxide anion radical by milk xanthine oxidase. Journal of Biological Chemistry., 1970, 245(16), 4053-4057.

44. Jasim, N. A.; Mehdi, W. A., Correlation between E3 SUMO-Protein Ligase NSE2 (NSMCE2) with 5'-nucleotidase, XOR, uric acid and total protein in patients with atherosclerosis. Advances in Natural and Applied Sciences., 2015, 9(2), 67-76.

45. Nishino, T., The conversion of xanthine dehydrogenase to xanthine oxidase and the role of the enzyme in reperfusion injury. The Journal of Biochemistry., 1994, 116(1), 1-6. 